\title{
A High Dose of Vitamin E Inhibits Adrenal Corticosterone Synthesis in Chickens Treated with ACTH
}

\author{
Nene TANiguchI, Akira OHTSUKa and Kunioki Hayashi* \\ Faculty of Agriculture, Kagoshima University, 1-21-24 Korimoto, \\ Kagoshima 890-0065, Japan
}

(Received August 2, 2000)

\begin{abstract}
Summary The present experiment was conducted to study the effects of dietary vitamin $\mathrm{E}$ on plasma corticosterone (CTC) concentration and adrenal steroid syntheses in chickens treated with adrenocorticotropic hormone (ACTH). Chickens were divided into ACTH(-) and $\mathrm{ACTH}(+)$ groups, and each group was further divided into three subgroups administered with vitamin E ( 500 or $5,000 \mathrm{mg} / \mathrm{kg}$ diet) and without the vitamin. Vitamin E (DL- $\alpha$ tocopheryl acetate) was mixed with the basal diet at levels of 500 and $5,000 \mathrm{mg} / \mathrm{kg}$ and fed for $6 \mathrm{~d}$. ACTH ( $20 \mathrm{IU} / \mathrm{kg}$ body weight) was given daily by intraperitoneal injection for $5 \mathrm{~d}$. $\alpha$ Tocopherol levels in the plasma and adrenal gland were markedly elevated by vitamin $\mathrm{E}$ feeding, and the level of adrenal free cholesterol (CHOL), which is used for steroid synthesis, was significantly decreased by vitamin $\mathrm{E}$ feeding in a dose-dependent manner. However, the level of adrenal CHOL ester was unchanged by any treatment. The elevations of pregnenolone, progesterone and CTC levels in the adrenal gland of chickens with ACTH treatment were decreased by vitamin $\mathrm{E}$ administration. The elevation of plasma CTC concentration in the $\mathrm{ACTH}(+)$ group was dramatically decreased by vitamin $\mathrm{E}$ administration, while that concentration was not influenced by the vitamin administration in the $\mathrm{ACTH}(-)$ group. These findings indicate that vitamin E suppresses the elevation of the plasma CTC concentration due to ACTH in chickens, possibly by inhibiting the conversion of CHOL ester to free CHOL in the adrenal gland.
\end{abstract}

Key Words adrenocorticotropic hormone, vitamin E, cholesterol, corticosterone

Restraint, fasting, transport and exposure to high or low environmental temperatures are typical stressors for animals. During stress, the hypothalamus-pituitaryadrenal axis is activated and glucocorticoid hormone is released from the adrenal cortex (1). Glucocorticoid is essential for maintaining life and normal growth. However, excessive glucocorticoid causes growth inhibition, muscle proteolysis, fat deposition (2), induction of oxidative stress $(3,4)$ and immune system suppression (5). Thus, minimizing stress is important not only in humans but also in farm animals.

Several studies have shown that vitamin E reduces plasma glucocorticoid levels under different types of stress in rats $(6-8)$. However, the mechanism accounting for this reduction remains unknown.

The pathway in the adrenal cortex leading from a steroid precursor (cholesterol, CHOL) to glucocorticoids involves several different forms of cytochrome P-450. The rate-limiting reaction in this pathway is the sidechain cleavage of CHOL to form pregnenolone (PREG) (9). This step is catalyzed by cytochrome P-450scc (10) located on the matrix side of the inner membrane (11), and is activated by adrenocorticotropic hormone $(\mathrm{ACTH})(9)$. Activity of this enzyme depends heavily on the amount of CHOL in adrenal glands (12-14). A de-

* To whom correspondence should be addressed.

E-mail: hayashi@chem.agri.kagoshima-u.ac.jp creased content of adrenal CHOL is correlated with a reduction in the steroid synthesis and exhaustion of free CHOL occurs rapidly, within a few minutes, by ACTH stimulation (14).

Arai (15) has reported that $\alpha$-tocopherol (TOC) transport may be linked to the cellular CHOL metabolism and/or transport in the liver cell. There are several clinical studies that reported that the plasma CHOL concentration is inversely proportional to the plasma vitamin E concentration (16-18). Recently, Traber and Packer (19) have reported that vitamin E may have a structure-specific role in addition to its antioxidant function.

The plasma concentration of TOC increases only 2or 3-fold even when the ingestion is about 100-fold in rats (20). This can be explained by the TOC transfer protein system that plays a key role in the preferential retention and the subsequent distribution of TOC to tissues (20). However, Leonhardt et al. (21) has reported that TOC accumulation in tissues is far greater in chickens than other animals. It is known that, in chickens, the plasma TOC concentration increases linearly in response to dietary intake and there is a high relationship between dietary and plasma TOC concentrations (22). From these findings, it was suggested that a large amount of vitamin E may decrease the adrenal free CHOL content and inhibit the stress-induced elevation of plasma corticosterone (CTC) concentration in chick- 
ens.

In the present study, we examined how a high dose of vitamin $\mathrm{E}$ affects the adrenal content of free CHOL and precursors of CTC and the plasma concentrations of CHOL and CTC in chickens treated with and without ACTH.

\section{MATERIALS AND METHODS}

Animal, diets and schedule. One-d-old male broiler chickens of the Cobb strain were supplied by a local commercial hatchery (Kumiai Hina Center, Kagoshima, Japan). They were housed in an electrically-heated battery brooder and were provided with water and a commercial starter diet (21\% CP; Minami Nihon Kumiai Shiryo Co., Kagoshima, Japan) ad libitum for the first 7 d. On day 7, chickens were selected from the two-fold large population for uniform body weight and divided into 6 groups with 6 replications of 2 chickens in each cage. Chickens were housed in wire-bottomed aluminum cages $(49 \mathrm{~cm}$ height $\times 40 \mathrm{~cm}$ width $\times 67 \mathrm{~cm}$ depth). The experiment was conducted in temperaturecontrolled rooms with a $14 \mathrm{~h}$ light $-10 \mathrm{~h}$ dark cycle. The temperature of the room was $25^{\circ} \mathrm{C}$, and relative humidity was maintained at $50-70 \%$ throughout the experiment. The composition of a basal diet $(3,200 \mathrm{kcal}$ $\mathrm{ME} / \mathrm{kg}$ and $23 \%$ crude protein) is shown in Table 1 . The basal diet was fed ad libitum during the preconditioning period (from 7 to $9 \mathrm{~d}$ of age).

On day 9, chickens were divided into $\operatorname{ACTH}(-)$ and $\mathrm{ACTH}(+)$ groups, and each group was further divided into E 0, E 500 and E 5,000 subgroups. E 500 and E 5,000 subgroups received the basal diets replaced with equivalent amounts of corn with 500 and 5,000 mg DL$\alpha$-tocopheryl acetate/kg, respectively. DL- $\alpha$-Tocopheryl acetate was purchased from Nacalai Tesque (Kyoto, Japan). Cortosyn Z, a synthetic ACTH, was purchased from Daiichi Pharmaceutical Co., Ltd. (Tokyo, Japan). Cortosyn $\mathrm{Z}$ contains a tetracosactide that is composed from 24 amino acids. ACTH was given at the level of $20 \mathrm{IU} / \mathrm{kg}$ body weight daily by intraperitoneal injection. An equivalent volume of saline was administered in the ACTH( $(-)$ group. The birds were treated with vitamin $\mathrm{E}$ from 9 to $15 \mathrm{~d}$ of age and ACTH was given from 11 to $15 \mathrm{~d}$ of age. Body weight and food intake were recorded daily. At the end of the experimental period, all birds were sacrificed by decapitation. Blood was collected into heparinized-test tubes, quickly centrifuged at $4,700 \times g$ for $10 \mathrm{~min}$ at $4^{\circ} \mathrm{C}$ to separate plasma, and stored at $-20^{\circ} \mathrm{C}$ until analysis. The birds were dissected to remove liver and both adrenal glands. The adrenal glands were stored at $-80^{\circ} \mathrm{C}$ until analysis.

TOC contents in plasma and adrenal gland. TOC contents in the plasma and adrenal gland were assayed using HPLC according to the method of Phoenix (23).

CHOL contents in plasma and adrenal gland. Plasma and adrenal CHOL contents and the adrenal free CHOL content were measured by an enzymatic CHOL assay system using a commercial kit, (Cholesterol E-Test Wako and Free Cholesterol E-Test Wako, Wako Pure Chemical Industries, Ltd., Osaka, Japan). After the adre-
Table 1. Composition of basal diet.

\begin{tabular}{lr}
\hline Ingredients & $\%$ \\
\hline Ground yellow corn & 71.66 \\
Dehydrated alfalfa meal & 3.77 \\
Purified soybean protein & 19.60 \\
Mineral mixture* & 3.31 \\
Vitamin mixture & 0.26 \\
L-Lysine & 0.28 \\
DL-Methionine & 0.32 \\
Soybean oil & 0.80 \\
Analysis & \\
Crude Protein, \% & 23 \\
ME & $3,200 \mathrm{kcal} / \mathrm{kg}$
\end{tabular}

* Contained (/kg): $\mathrm{CaCO}_{3} 110 \mathrm{~g}, \mathrm{CaHPO}_{4} 660 \mathrm{~g}, \mathrm{NaCl}$ $113 \mathrm{~g}, \mathrm{MnSO}_{4} \cdot 4-5 \mathrm{H}_{2} \mathrm{O} \quad 6.600 \mathrm{~g}, \mathrm{ZnSO}_{4} \cdot 7 \mathrm{H}_{2} \mathrm{O} 4.000 \mathrm{~g}$, $\mathrm{FeSO}_{4} 6.145 \mathrm{~g}, \mathrm{CuSO}_{4} \cdot 7 \mathrm{H}_{2} \mathrm{O} 233 \mathrm{mg}, \mathrm{NaIO}_{3} 16 \mathrm{mg}$, and $\mathrm{H}_{2} \mathrm{SeO}_{3} 6 \mathrm{mg}$.

† Contained $(/ \mathrm{kg})$ : retinol $1,750,000 \mathrm{IU}$, cholecalciferol $200,000 \mathrm{IU}$, riboflavin $2.5 \mathrm{~g}$, thiamine $1 \mathrm{~g}$, pyridoxine $0.5 \mathrm{~g}$, cyanocobalamin $10 \mathrm{mg}$, pantothenic acid $4 \mathrm{~g}$, nicotinic acid $10 \mathrm{~g}$, menadione $250 \mathrm{mg}$, folic acid $200 \mathrm{mg}$, choline chloride $300 \mathrm{mg}$, biotin $25 \mathrm{mg}$, DL- $\alpha$-tocopheryl acetate $2.5 \mathrm{~g}$, and sucrose $978 \mathrm{~g}$.

nal gland was homogenized with saline using a polytron homogenizer, the homogenate was provided for the measurement. The CHOL ester content was calculated by subtracting free CHOL from total CHOL.

Plasma CTC concentration. Plasma CTC concentration was measured by a radioimmunoassay using a commercial kit (ICN Biomedicals, Inc., California, USA).

HPLC analyses of steroids. According to the method of Neri et al. (24), steroid assays were carried out with minor modifications. The outline of the procedure is as follows. Adrenal homogenates were mixed with $100 \mu \mathrm{L}$ of a dexamethasone (100 ng) solution that was used as an internal standard and a recovery marker. Then steroids were extracted from the homogenate by mixing with $0.6 \mathrm{~mL} 0.25 \mathrm{M} \mathrm{NaOH}$ and $6 \mathrm{~mL}$ dichloromethane for $1 \mathrm{~min}$ before centrifuging at $4,700 \times \mathrm{g}$ for $10 \mathrm{~min}$. After pipetting out the lipid layer, the extract was washed with $10 \mathrm{~mL} 0.1 \mathrm{M} \mathrm{NaOH}$ and $15 \mathrm{~mL}$ distilled water, and then evaporated to dryness under a vacuum and redissolved in $300 \mu \mathrm{L} \mathrm{58 \%} \mathrm{methanol.} \mathrm{This} \mathrm{solution}$ was used for the analyses of PREG, progesterone (PROG), 11-deoxycorticosterone (DOC) and CTC. The steroids were assayed according to the HPLC method of O'Hare et al. (25) using a Shimadzu LC-10AD equipped with a Shim-Pack CLC-ODS column $(6.0 \times 150 \mathrm{~nm})$; the reproducibility of the retention time was $1-3 \%$ (coefficient of variation). Steroid hormones were monitored by a Tosoh UV-8010 spectrometer. PREG and PROG were detected at $290 \mathrm{~nm}$ and DOC and CTC at $248 \mathrm{~nm}$. The compositions of the mobile phases were $\mathrm{MeOH}$ : $\mathrm{H}_{2} \mathrm{O}=80: 20$ for analyzing PREG and PROG, and $58: 42$ for DOC and CTC. Steroids were identified by comparison of their retention times with those of the standards. Moreover, for the initial identification, the 
same sample was chromatographed alone or with the addition of the standards; this procedure was used during the routine analysis to confirm the findings of some difficult samples. Quantification of steroid hormones was based on peak-area measurement using a Shimadzu C-R6A Chromatopac.

Statistical analyses. Data were analyzed by two-way analysis of variance (ANOVA) using the General Liner Model procedure of the statistical analysis system software package (Release 6.09, SAS Institute Inc., Cary, NC, USA) with Duncan's multiple-range test. A $p$ value $<0.05$ was considered to be statistically significant.

\section{RESULTS}

The body weight gain, feed intake and feed efficiency during the period of 4 to $11 \mathrm{~d}$ of age, and adrenal gland weight in chickens are shown in Table 2. The body weight gain tended to decrease when the birds were treated with ACTH, and vitamin E administration tended to minimize the ACTH effect. Feed intake was not changed by any treatment and, thus, the feed efficiency tended to be lower in the ACTH group. This effect of ACTH also tended to be minimized by vitamin $\mathrm{E}$ administration. Adrenal gland weight was not changed by any treatment.

The effect of dietary vitamin $\mathrm{E}$ on TOC and CHOL

Table 2. Effect of vitamin E on body weight gain, feed intake, feed conversion ratio and adrenal gland weight in chickens treated with and without $\mathrm{ACTH}^{1}$.

\begin{tabular}{|c|c|c|c|c|c|}
\hline Treatment $^{2}$ & $\begin{array}{l}\text { Vitamin } \mathrm{E}^{3} \\
\quad(\mathrm{mg})\end{array}$ & $\begin{array}{l}\text { Body weight gain } \\
\text { (g/4 d/pen) }\end{array}$ & $\begin{array}{l}\text { Feed intake } \\
(\mathrm{g} / 4 \mathrm{~d} / \text { pen })\end{array}$ & $\begin{array}{l}\text { Feed efficiency } \\
\qquad(4 \mathrm{~d})\end{array}$ & $\begin{array}{l}\text { Adrenal weight } \\
(\mathrm{mg} / 100 \mathrm{~g} \mathrm{BW})\end{array}$ \\
\hline \multirow[t]{3}{*}{$\operatorname{ACTH}(-)$} & 0 & $223 \pm 34$ & $321 \pm 27$ & $0.69 \pm 0.06$ & $9.8 \pm 1.4$ \\
\hline & 500 & $210 \pm 38$ & $297 \pm 38$ & $0.68 \pm 0.09$ & $10.3 \pm 1.9$ \\
\hline & 5,000 & $208 \pm 32$ & $308 \pm 19$ & $0.70 \pm 0.05$ & $11.1 \pm 1.3$ \\
\hline \multirow[t]{3}{*}{$\operatorname{ACTH}(+)$} & 0 & $188 \pm 34$ & $307 \pm 24$ & $0.63 \pm 0.06$ & $10.5 \pm 2.6$ \\
\hline & 500 & $208 \pm 29$ & $298 \pm 55$ & $0.68 \pm 0.08$ & $9.5 \pm 1.9$ \\
\hline & 5,000 & $211 \pm 39$ & $284 \pm 51$ & $0.72 \pm 0.07$ & $10.4 \pm 2.6$ \\
\hline \multicolumn{6}{|l|}{ ANOVA $^{4}$} \\
\hline ACTH & & NS & NS & NS & NS \\
\hline Vitamin E & & NS & NS & NS & NS \\
\hline ACTH $\times$ vitamin $E$ & & NS & NS & NS & NS \\
\hline
\end{tabular}

\footnotetext{
${ }^{1}$ Values are expressed as means $\pm \mathrm{SD}, n=6$. Means in columns followed by different letters are significantly different, $p<0.05$.

${ }^{2} \mathrm{ACTH}(-)$ and $\mathrm{ACTH}(+)$ groups were intraperitonealy injected with saline and $20 \mathrm{IU} \mathrm{ACTH} / \mathrm{kg}$ body weight everyday for $5 \mathrm{~d}$, respectively.

${ }^{3}$ Chickens were fed a diet containing 0,500 or $5,000 \mathrm{mg}$ DL- $\alpha$-tocopheryl acetate $/ \mathrm{kg}$ diet.

${ }^{4}$ Two-way analysis of variance.
}

Table 3. Effect of vitamin E on TOC and CHOL levels in plasma and adrenal gland and adrenal free CHOL level in chickens treated with and without $\mathrm{ACTH}^{1}$.

\begin{tabular}{|c|c|c|c|c|c|c|}
\hline \multirow{2}{*}{ Treatment $^{2}$} & \multirow{2}{*}{$\begin{array}{l}\text { Vitamin } \mathrm{E}^{3} \\
(\mathrm{mg})\end{array}$} & \multicolumn{2}{|c|}{ Plasma } & \multicolumn{3}{|c|}{ Adrenal } \\
\hline & & $\begin{array}{c}\text { TOC } \\
(\mu \mathrm{g} / \mathrm{mL})\end{array}$ & $\begin{array}{c}\text { CHOL } \\
(\mathrm{mg} / \mathrm{mL})\end{array}$ & TOC & $\begin{array}{l}\text { CHOL ester } \\
(\mu \mathrm{g} / \mathrm{adrenal})\end{array}$ & free CHOL \\
\hline \multirow[t]{3}{*}{$\operatorname{ACTH}(-)$} & 0 & $0.5 \pm 0.2^{c}$ & $1.73 \pm 0.31^{\mathrm{ab}}$ & $0.30 \pm 0.14^{\mathrm{c}}$ & $83.9 \pm 33.6$ & $101.1 \pm 22.1^{a}$ \\
\hline & 500 & $9.1 \pm 4.2^{\mathrm{b}}$ & $1.80 \pm 0.26^{\mathrm{ab}}$ & $5.53 \pm 2.06^{b}$ & $89.7 \pm 14.1$ & $68.2 \pm 18.3^{\mathrm{b}}$ \\
\hline & 5,000 & $22.6 \pm 9.1^{\mathrm{a}}$ & $1.50 \pm 0.14^{\mathrm{b}}$ & $13.47 \pm 4.32^{\mathrm{a}}$ & $105.5 \pm 68.4$ & $32.5 \pm 5.9^{\mathrm{cd}}$ \\
\hline \multirow[t]{3}{*}{$\operatorname{ACTH}(+)$} & 0 & $0.5 \pm 0.2^{\mathrm{c}}$ & $1.78 \pm 0.20^{\mathrm{ab}}$ & $0.37 \pm 0.08^{c}$ & $83.2 \pm 37.3$ & $55.8 \pm 22.2^{\mathrm{bc}}$ \\
\hline & 500 & $9.9 \pm 5.7^{b}$ & $2.01 \pm 0.32^{\mathrm{a}}$ & $5.76 \pm 3.97^{b}$ & $63.3 \pm 28.2$ & $29.4 \pm 10.0^{\mathrm{d}}$ \\
\hline & 5,000 & $28.5 \pm 7.5^{\mathrm{a}}$ & $1.54 \pm 0.18^{\mathrm{b}}$ & $15.17 \pm 3.52^{\mathrm{a}}$ & $69.2 \pm 23.7$ & $20.4 \pm 6.6^{\mathrm{d}}$ \\
\hline \multicolumn{7}{|l|}{ ANOVA $^{4}$} \\
\hline ACTH & & NS & NS & NS & NS & 0.0001 \\
\hline Vitamin E & & 0.0001 & 0.003 & 0.0001 & NS & 0.0001 \\
\hline ACTH $\times$ vitamin $\mathrm{E}$ & & NS & NS & NS & NS & NS \\
\hline
\end{tabular}

${ }^{1}$ Values are expressed as means $\pm S D, n=6$. Means in columns followed by different letters are significantly different, $p<0.05$.

${ }^{2} \mathrm{ACTH}(-)$ and $\mathrm{ACTH}(+)$ groups were intraperitoneally injected with saline and $20 \mathrm{IU} \mathrm{ACTH} / \mathrm{kg}$ body weight everyday for $5 \mathrm{~d}$, respectively.

${ }^{3}$ Chickens were fed a diet containing 0,500 or 5,000 mg DL- $\alpha$-tocopheryl acetate/kg diet.

${ }^{4}$ Two-way analysis of variance. 
A)

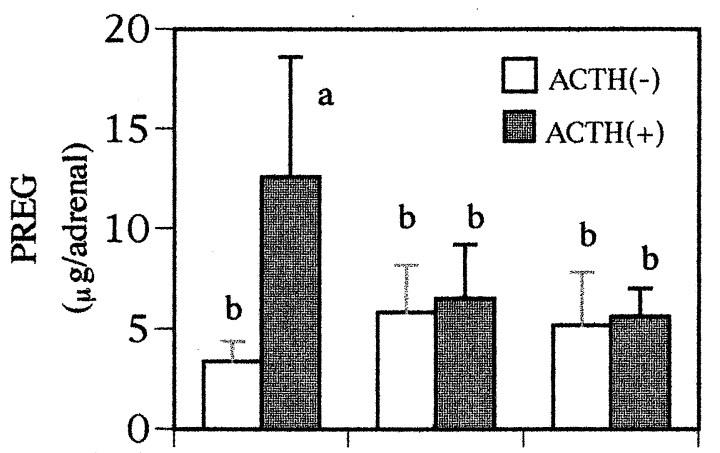

B)

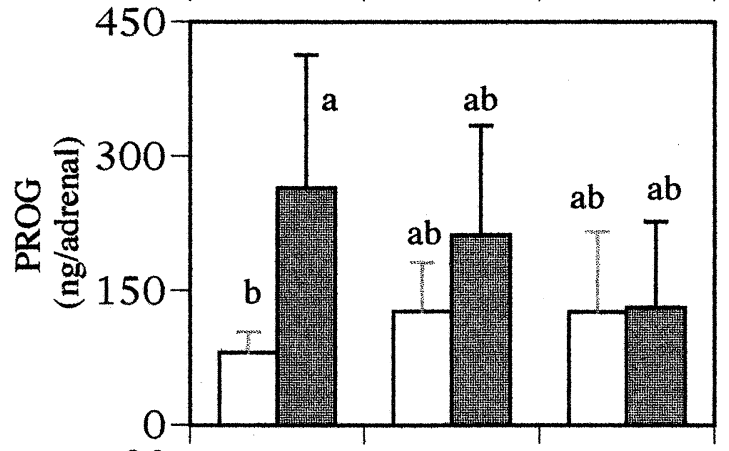

C)

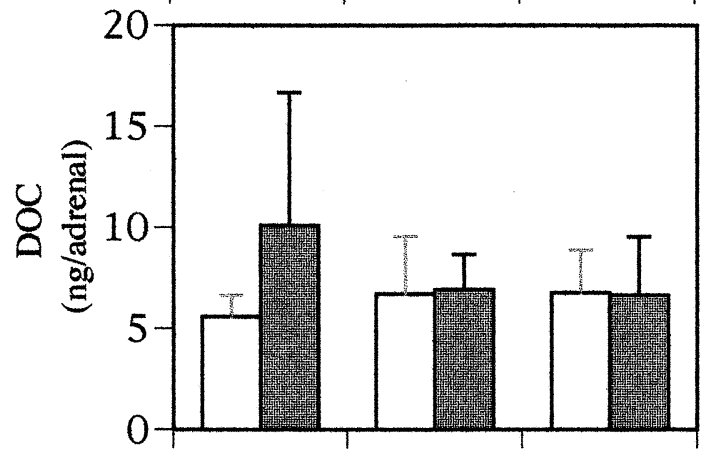

D)

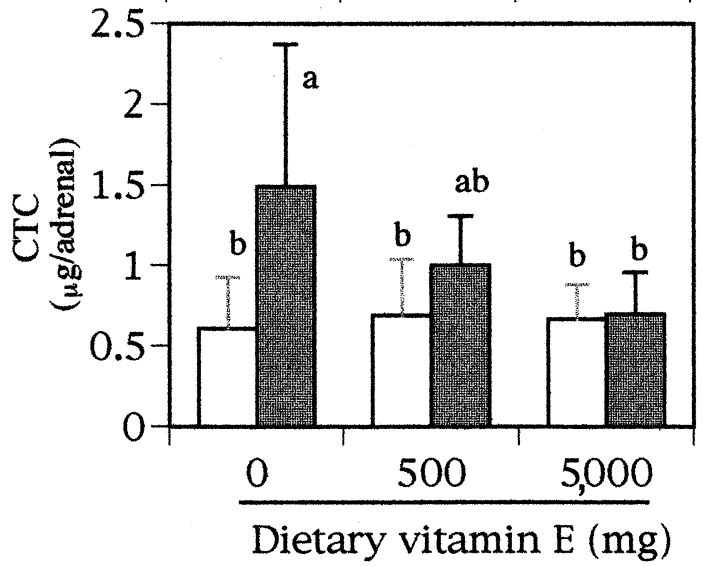

Fig. 1. Effect of vitamin $\mathrm{E}$ on adrenal contents of PREG (A), PROG (B), DOC (C) and CTC (D) levels in chickens treated with and without $\mathrm{ACTH}$. $\mathrm{ACTH}(-)$ and $\mathrm{ACTH}(+)$ groups were intraperitoneally injected with saline and $20 \mathrm{IU} \mathrm{ACTH} / \mathrm{kg}$ body weight everyday for $5 \mathrm{~d}$, respectively. Chickens were fed a diet containing 0 , 500 or $5,000 \mathrm{mg}$ DL- $\alpha$-tocopheryl acetate $/ \mathrm{kg}$. Values are expressed as means \pm SD. Means bearing different letters are significantly different $(p<0.05)$.

\begin{tabular}{lcccc}
\hline \multicolumn{1}{c}{ ANOVA } & PREG & PROG & DOC & CTC \\
\hline ACTH & 0.05 & 0.05 & NS & 0.05 \\
Vitamin E & NS & NS & NS & NS \\
ACTH $\times$ Vitamin E & 0.05 & NS & NS & NS \\
\hline
\end{tabular}

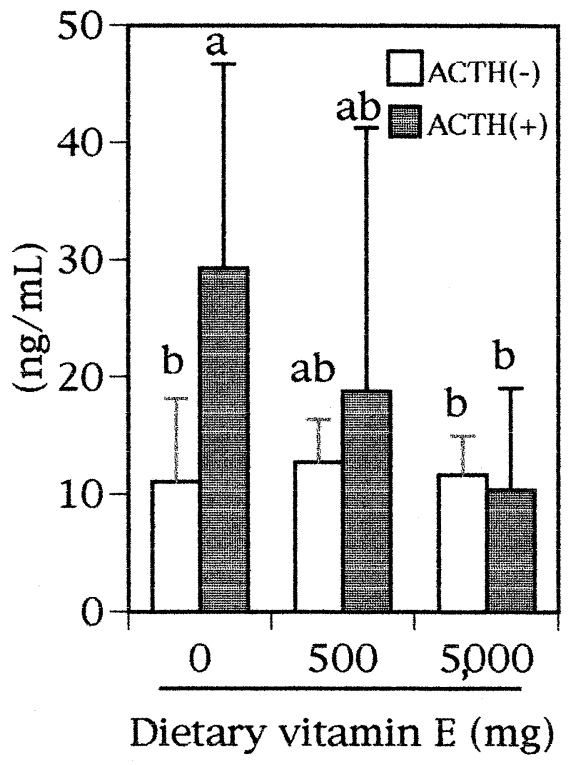

Fig. 2. Effect of vitamin $\mathrm{E}$ on plasma CTC level in chickens treated with and without ACTH. ACTH(-) and $\mathrm{ACTH}(+)$ groups were intraperitoneally injected with saline and $20 \mathrm{IU}$ ACTH $/ \mathrm{kg}$ body weight everyday for $5 \mathrm{~d}$, respectively. Chickens were fed a diet containing 0,500 or $5,000 \mathrm{mg} \mathrm{DL}-\alpha$-tocopheryl acetate $/ \mathrm{kg}$. Values are expressed as means \pm SD. Means bearing different letters are significantly different $(p<0.05)$.

\begin{tabular}{ll}
\hline ANOVA & \\
\hline ACTH & NS \\
Vitamin E & NS \\
ACTH $\times$ Vitamin E & NS \\
\hline
\end{tabular}

concentrations in the plasma and adrenal glands of chickens treated with and without ACTH are shown in Table 3. Plasma and adrenal TOC levels in the ACTH(-) and $\mathrm{ACTH}(+)$ groups were markedly elevated by vitamin $\mathrm{E}$ administration $(p<0.0001)$ in a dose-dependent manner, and a significant effect of dietary vitamin $\mathrm{E}$ was shown by ANOVA. The plasma CHOL concentration was decreased by a high dose of vitamin E administration in both $\mathrm{ACTH}(-)$ and $\mathrm{ACTH}(+)$ groups, and a significant effect of dietary vitamin $\mathrm{E}$ was shown by ANOVA. There was no significant difference in adrenal CHOL ester content between groups. However, the adrenal free CHOL content was decreased in the ACTH(+) group and it was further decreased in the ACTH(+) group with vitamin $\mathrm{E}$ administration, although that content was decreased in the $\mathrm{ACTH}(-)$ group with vitamin E administration. ANOVA showed that the effects of $\mathrm{ACTH}$ and vitamin $\mathrm{E}$ on the adrenal free CHOL content were significant $(p<0.0001)$. ACTH treatment increased the adrenal PREG and PROG contents and vitamin $\mathrm{E}$ administration minimized both increases, although neither ACTH treatment nor vitamin E administration had any significant effect on the adrenal DOC content (Fig. 1). ANOVA showed that the effect of ACTH on the PREG and PROG contents and the effect of a combination of ACTH and vitamin E on the PREG con- 
A)

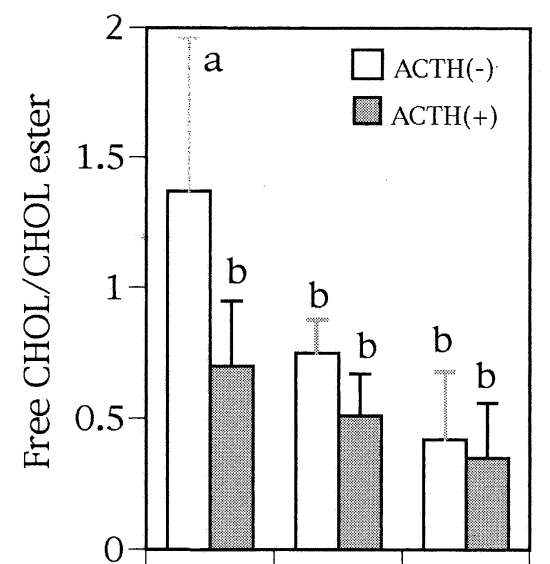

B)

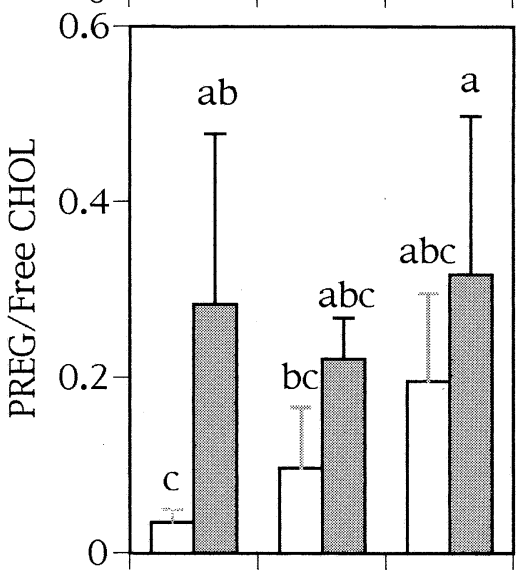

C)

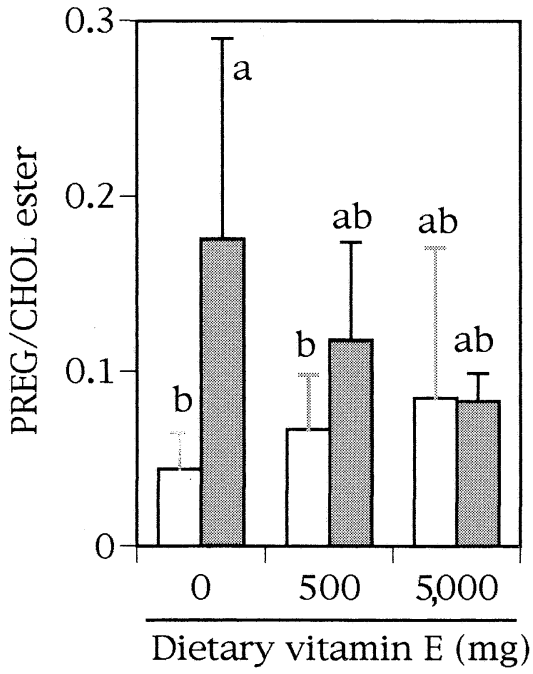

Fig. 3. Effect of vitamin $\mathrm{E}$ on ratios of free $\mathrm{CHOL} / \mathrm{CHOL}$ (A), PREG/free CHOL (B) and PREG/CHOL ester (C) in chickens treated with and without ACTH. ACTH(-) and $\mathrm{ACTH}(+)$ groups were intraperitoneally injected with saline and $20 \mathrm{IU}$ ACTH/kg body weight everyday for $5 \mathrm{~d}$, respectively. Chickens were fed a diet containing 0,500 or $5,000 \mathrm{mg}$ DL- $\alpha$-tocopheryl acetate $/ \mathrm{kg}$. Values are expressed as means \pm SD. Means bearing different letters are significantly different $(p<0.05)$.

\begin{tabular}{lccc}
\hline \multicolumn{1}{c}{ ANOVA } & $\begin{array}{c}\text { Free } \\
\text { CHOL/CHOL } \\
\text { ester }\end{array}$ & $\begin{array}{c}\text { PREG/Free PREG/CHOL } \\
\text { CHOL }\end{array}$ & ester \\
\hline ACTH & 0.05 & 0.003 & 0.05 \\
Vitamin E & 0.01 & NS & NS \\
ACTH $\times$ Vitamin E & NS & NS & NS \\
\hline
\end{tabular}

tent were significant. The adrenal CTC content was significantly increased 2.4-fold by ACTH treatment, and vitamin $\mathrm{E}$ administration significantly inhibited this increase in a dose-dependent manner (Fig. 1). When a quantitative comparison of the effect of vitamin $\mathrm{E}$ on adrenal steroid contents was performed in the 5,000 mg E group with ACTH treatment as shown in Fig. 1, vitamin $\mathrm{E}$ administration similarly inhibited the ACTHstimulated syntheses of adrenal PREG, PROG, DOC and CTC, i.e., PREG $(-55.6 \%)$, PROG $(-50.6 \%)$, DOC $(-34.2 \%)$ and CTC $(-53.0 \%)$. As shown in Fig. 2, the plasma CTC concentration was increased 2.6 -fold by ACTH treatment, and vitamin $\mathrm{E}$ feeding inhibited the ACTH-stimulated elevation of plasma CTC. The ratios of free CHOL/CHOL ester, PREG/free CHOL and PREG/ CHOL ester in the adrenal gland are shown in Fig. 3. The ratios were all changed by ACTH treatment, and ANOVA showed that the effects of ACTH on these ratios were significant $(p<0.05)$. On the other hand, vitamin $\mathrm{E}$ administration affected only the free $\mathrm{CHOL} / \mathrm{CHOL}$ ester ratio and ANOVA showed that the effect of vitamin E was significant $(p<0.05)$.

\section{DISCUSSION}

When an animal is exposed to noxious or potentially noxious stimuli, there is an increased secretion of ACTH and, consequently, a rise in the circulating glucocorticoid level. ACTH stimulates CTC synthesis via the mediation of adenylate cyclase and protein kinase in adrenal glands. Excessive glucocorticoid causes growth inhibition, muscle proteolysis, fat deposition (5), induction of oxidative stress $(6,7)$ and immune system suppression (8). Therefore, relief of stress is important not only in humans but also in animals.

Vitamin $\mathrm{E}$ is a strong candidate as an anti-stress agent. However, there are few and rather conflicting findings on the effect of vitamin $\mathrm{E}$ on glucocorticoid secretions. Ni et al. (26) reported that vitamin E enhanced ACTH-induced glucocorticoids synthesis in rat adrenal gland. However, al-Shabanah et al. (7) and Shaheen et al. (8) reported that an increase in plasma corticosterone concentration by bacterial endotoxin and swimming stress could be diminished by vitamin $\mathrm{E}$ in rats. In contrast, Armario et al. $(27,28)$ reported that vitamin $\mathrm{E}$ did not modify the pituitary-adrenal activity in rats with immobilization stress. Nakamura (29) reported that adrenal function is activated by a small amount of vitamin $\mathrm{E}$ but is inhibited by a large amount of the vitamin in rabbits.

The present study clearly shows that an increase in plasma CTC level due to ACTH is diminished in chickens by a high dose of vitamin $\mathrm{E}$. Thus, it was suggested that vitamin E might directly reduce CTC synthesis in the adrenal gland. To examine this hypothesis, we measured adrenal steroids in chickens treated with ACTH.

In chickens, the major corticosteroid present in the adrenal gland is CTC because little $17 \alpha$-hydroxylase activity exists in the adrenal gland and therefore cortisol cannot be synthesized (30). Steroids produced in the adrenal cortex are derivatives of CHOL. Adrenocortical 
cells are almost completely dependent upon the continuous supply of CHOL from serum lipoproteins (31). CHOL is esterified and stored as lipid droplets in adrenocortical cells before synthesizing steroids. CHOL esterase hydrolyzes CHOL ester to free CHOL before conversion of free CHOL to PREG in adrenal mitochondria by $\mathrm{P}-450 \mathrm{scc}$ which is activated by ACTH. In adrenal glands, PREG produced from CHOL is converted to PROG and the PROG is further hydroxylated to give DOC. The DOC is finally hydroxylated to form CTC in adrenal glands. There are studies showing the effect of vitamin E deficiency on steroidgenesis (32-34). However, little attention has been paid to the effect of a high dose of vitamin $\mathrm{E}$ on steroidgenesis.

Analyses of steroids in the adrenal gland of chickens suggest that the decrease in CTC synthesis due to vitamin $\mathrm{E}$ was caused by depletion of free CHOL in the adrenal gland.

Plasma and adrenal TOC levels in the vitamin E-administered chickens $(5,000 \mathrm{mg} / \mathrm{kg})$ with and without ACTH treatment were about 50-fold higher than their control levels. This is consistent with the findings of Leonhardt et al. (21) who showed that TOC accumulation in tissues was greater in chickens than in other animals. Although the plasma CHOL concentration in chickens treated with and without ACTH was decreased by a high dose of vitamin $\mathrm{E}(5,000 \mathrm{mg} / \mathrm{kg})$, the adrenal CHOL ester content was not changed by the vitamin $\mathrm{E}$ administration. However, the adrenal free CHOL content in chickens treated with and without ACTH was significantly decreased by vitamin E administration in a dose-dependent manner (Table. 3). The PREG/free CHOL ratio in the adrenal gland of chickens was clearly increased by ACTH treatment (Fig. 3-B). This suggests that the decrease in free CHOL content due to ACTH in the adrenal gland of chickens may be caused by an increase in PREG formation in the gland. However, vitamin $\mathrm{E}$ administration did not change this ratio significantly. Thus, it is obvious that the decrement of adrenal free CHOL content due to vitamin $\mathrm{E}$ was caused by the reduction of the formation of free CHOL from CHOL ester. The effect of vitamin $\mathrm{E}$ on the free CHOL/CHOL ester ratio in the adrenal gland of chickens was significant, but that on the PREG/free CHOL ratio was not (Fig. 3). The levels of adrenal PREG, PROG, DOC and CTC were all lowered by vitamin $\mathrm{E}$ administration in ACTH-treated chickens (Fig. 1). These findings clearly indicate that the inhibition of CTC synthesis by vitamin E occurs at the step of free CHOL formation in the adrenal gland of chickens treated with ACTH. Although vitamin $\mathrm{E}$ administration decreased adrenal free $\mathrm{CHOL}$ content in ACTH-untreated chickens, an inhibition of adrenal CTC synthesis was not shown, because adrenal PREG synthesis in the chickens was stimulated, but not significantly, by vitamin E administration (Fig. 3-B).

Deficiency of CHOL leads to insufficient synthesis of adrenal steroid hormones $(12-14,35)$. These observations are consistent with the findings in the present study.

The present investigation showed that a high dose of vitamin E minimizes the elevation of plasma CTC level due to ACTH in chickens, possibly by inhibiting the conversion of CHOL ester to free CHOL in the adrenal gland. Measurement of activities of enzymes regulating this step in the adrenal gland, e.g., CHOL esterase and P$450 \mathrm{scc}$, is in progress in our laboratory. Furthermore, our previous study has shown that CTC induces oxidative stress and that this effect of CTC can be minimized by a high dose of vitamin E (7). Thus, the present study suggests that vitamin $\mathrm{E}$ works as a strong anti-stress agent.

\section{REFERENCES}

1) Klemcke HG, Nienaber JA, Hahn GL. 1989. Plasma adreno corticotropic hormone and cortisol in pigs: Effects of time of day on basal and stressor-altered concentrations. Proc Soc Exp Biol Med 190: 42-53.

2) Hayashi K, Nagai A, Ohtska A, Tomita Y. 1994. Effects of dietary corticosterone and trilostane on growth and skeletal muscle protein turnover in broiler cockerels. $\mathrm{Br}$ Poul Sci 35: 789-798.

3) Ohtsuka A, Ohtani T, Horiguchi H, Kojima H, Hayashi K. 1998. Vitamin E reduces glucocorticoid-induced growth inhibition and lipid peroxidation in rats. J Nutr Sci Vitaminol 44: 237-247.

4) Taniguchi N, Ohtsuka A, Hayashi K. 1999. Effect of dietary corticosterone and vitamin $\mathrm{E}$ on growth and oxidative stress in broiler chickens. Anim Sci J 70: 195-200.

5) Crabtree GR, Gillis S, Smith KA, Munck A. 1979. Glucocorticoids and immune responses. Arthritis Rheum 22: 1246-1256.

6) Lim TS, Putt N, Safranski D, Chung C, Watson RR. 1981. Effect of vitamin E on cell-mediated immune responses and serum corticosterone in young and maturing mice. Immunology 44: 289-295.

7) al-Shabanah OA, Mostafa YH, Hassan MT, Khairaldin AA, al-Sawaf HA. 1996. Vitamin E protects against bacterial endotoxin-induced increase of plasma corticosterone and brain glutamate in the rat. Res Commun Mol Pathol Pharmacol 92: 95-105.

8) Shaheen AA, Hamdy MA, Kheir-Eldin AA, Lindstrom P, el-Fattah AA. 1993. Effect of pretreatment with vitamin E or diazepam on brain metabolism of stressed rats. Biochem Pharmacol 46: 194-197.

9) Stone D, Hechter O. 1954. Studies on ACTH action n perfused bovine adrenals: the site of action of ACTH in corticosteroidgenesis. Arch Biochem Biophys 51: 457-469.

10) Simpson ER, Boyd GS. 1967. Partial resolution of the mixed-function oxidase involved in the cholesterol sidechain cleavage reaction in bovine adrenal mitochondria. Biochem Biophys Res Commun 28: 945-950.

11) Mitani F, Iizuka T, Ueno R, Ishimura $Y$, Kimura $T$, Izumi S, Komatsu N, Watanabe K. 1982. Regulation of cytochrome $\mathrm{P} 450$ activities in adrenocortical mitochondria from normal rats and human neoplastic tissues. Adv Enzyme Regul 20: 213-231.

12) Privalle CT, Crivello JF, Jefcoate CR. 1983. Regulation of intramitochondrial cholesterol transfer to side-chain cleavage cytochrome P-450 in rat adrenal gland. Proc Natl Acad Sci USA 80: 702-706.

13) Crivello JF, Jefcoate CR. 1980. Intracellular movement of cholesterol in rat adrenal cells. Kinetics and effects of 
inhibitors. J Biol Chem 255: 8144-8151.

14) Hall PF. 1984. Cellular organization for steroidogenesis. Int Rev Cytol 86: 53-95.

15) Arai H. 1998. Mechanisms for the transport of alphatocopherol mediated by alpha-tocopherol transfer protein in the liver cell. Vitamins 72: 353-361.

16) Wilson RB, Middleton CC, Sun GY. 1978. Vitamin E, antioxidants and lipid peroxidation in experimental atherosclerosis of rabbits. J Nutr 108: 1858-1867.

17) Komaratat P, Chupukcharoen N, Wilairat P. 1985. Effect of vitamin $\mathrm{E}$ on cholesterol plasma lipoprotein distribution and metabolism in rabbit. Int J Vitam Nutr Res 55: 167-171.

18) Chen LH, Liaom S, Packett LV. 1972. Interaction of dietary vitamin $\mathrm{E}$ and protein level of lipid source with serum cholesterol level in rats. J Nutr 102: 729-732.

19) Traber MG, Packer L. 1995. Vitamin E: beyond antioxidant function. Am J Clin Nutr 62: 1501S-1509S.

20) Arai H. 1997. Structure and Function alpha-tocopherol Transfer Protein-Major Determinant of Plasma Vitamin E Level一. Vitamins 71: 17-28.

21) Leonhardt M, Gebert S, Wenl C. 1997. Vitamin E content of different animal products: Influence of animal nutrition. Z Ernahrungswiss 36: 23-27.

22) Sheehy PJ, Morrissey PA, Flynn A. 1991. Influence of dietary alpha-tocopherol on tocopherol concentrations in chick tissues. Br Poul Sci 32: 391-397.

23) Phoenix J, Edwards RH, Jackson MJ. 1990. Effects of calcium ionophore on vitamin E-deficient rat muscle. Br J Nutr 64: 245-256.

24) Neri G, Malendowicz LK, Andreis P, Nussdorfer GG. 1993. Thyrotropin-releasing hormone inhibits glucocorticoid secretion of rat adrenal cortex: in vivo and in vitro studies. Endocrinology 133: 511-514.

25) O'Hare MJ, Nice EC, Magee-Brown R, Bullman H. 1976. High-pressure liquid chromatography of steroids secreted by human adrenal and testis cells in monolayer culture. J Chromatogr 125: 357-367.

26) Ni H, Mune T, Morita H, Daidoh H, Hanafusa J, Shibata
T, Yamakita N, Yasuda K. 1995. Inhibition of aldosterone turn-off phenomenon following chronic adrenocorticotropin treatment with in vivo administration of antiglucocorticoid and antioxidants in rats. Eur $J$ Endocrinol 133: 578-584.

27) Armario A, Campmany L, Borras M, Hidalgo J. 1990. Vitamin E-supplemented diets reduce lipid peroxidation but do not alter either pituitary-adrenal, glucose, and lactate responses to immobilization stress or gastric ulceration. Free Radic Res Commun 9: 277-280.

28) Armario A, Borras M, Campmany L. Lack of effect of alpha-tocopherol and ascorbic acid on the response of some physiological variables to immobilization stress in rat. 1989. Rev Esp Fisiol 45: 277-280.

29) Nakamura Y. 1965. Endocrine function and vitamin E; on assay of 17-ketosteroids in rabbit urine. Nippon Sanka Fujinka Zassi 17: 479-488.

30) Nakamura T, Tanabe Y. 1973. In vitro corticosteroidogenesis by the adrenal gland of the chicken (Gallus domesticus). Gen Comp Endocrinol 21: 99-107.

31) Mazzocchi G, Rebuffat P, Belloni AS, Gottardo G, Meneghelli V, Nussdorfer GG. 1988. Effects of mevinolin, an inhibitor of cholesterol synthesis, on the morphological and functional responses of rat adrenal zona fasciculata to a prolonged treatment with 4-aminopyrazolo-pyrimidine. Anat Rec 221: 700-706.

32) Barnes MM, Smith AJ. 1975. The effect of vitamin E deficiency on androgen and corticosterone synthesis. Int $J$ Vitam Nutr Res 45: 342-348.

33) Barnes MM, Smith AJ. 1975. The effects of vitamin E deficiency on some enzymes of steroid hormone biosynthesis. Int J Vitam Nutr Res 45: 396-403.

34) Smith AJ, Barnes MM. 1976. Some aspects of steroidogenesis in the vitamin $\mathrm{E}$ deficient rat. Int $J$ Vitam Nutr Res 46: 248-250.

35) Andersson HC, Frentz J, Martinez JE, Tuck-Muller CM, Bellizaire J. 1999. Adrenal insufficiency in SmithLemli-Opitz syndrome. Am J Med Genet 82: 382-384. 